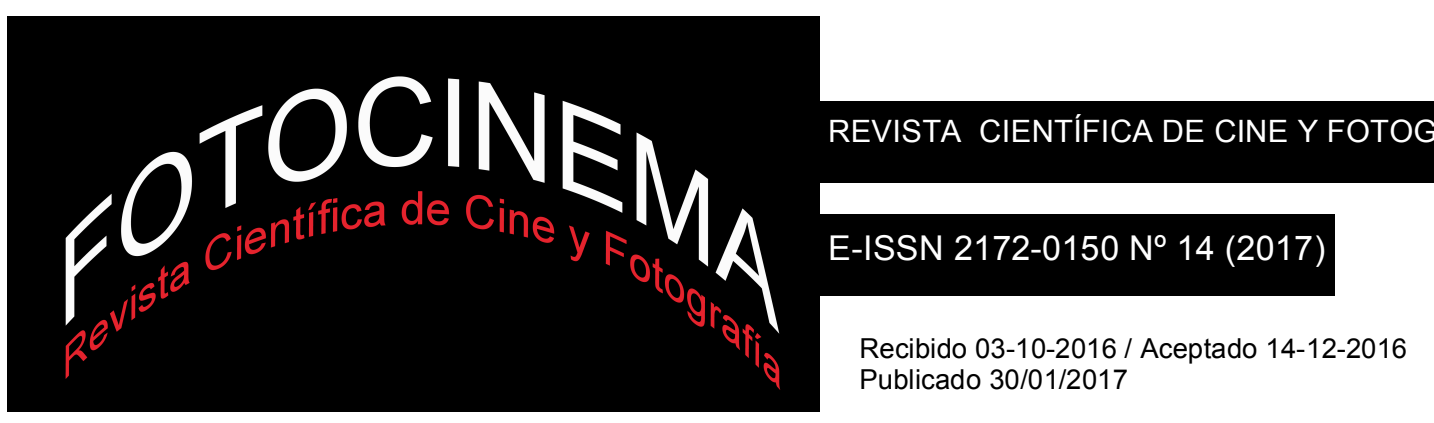

\title{
EL NACIONALISMO CULTURAL MEXICANO Y SUS CONTRADICCIONES EN LA PELÍCULA VÁMONOS CON PANCHO VILLA
}

\section{MEXICAN CULTURAL NATIONALISM AND ITS CONTRADICTIONS IN THE MOVIE VÁMONOS CON PANCHO VILLA}

\author{
Vicente de Jesús Fernández Mora \\ Universidad Autónoma de Aguascalientes, México \\ vicjesfm@hotmail.com
}

\section{Resumen:}

El presente artículo pretende revisar uno de los hitos fundamentales del nacionalismo revolucionario mexicano de los años 30 del pasado siglo, la película Vámonos con Pancho Villa, dirigida por Fernando de Fuentes en 1936, en la que se dieron cita algunos de los más representativos exponentes de la cultura mexicana del momento, en las tareas de guión, música o dirección. Esta película fue concebida como un proyecto subvencionado por el Estado para exaltar los valores en los que se había fundado tanto la Revolución mexicana como la propia legitimidad del gobierno en el poder, pero una reflexión atenta sobre la novela que dio origen a la producción cinematográfica, como sobre la propia cinta, su guión o su banda sonora original, así como la propia trayectoria y logros personales de los artistas involucrados en el proyecto, nos revelan una tensiones y contradicciones que ponen en entredicho la solvencia ideológica del discurso oficial revolucionario.

\begin{abstract}
:
This article aims to review one of the milestones of Mexican revolutionary nationalism of the 30 s of last century, the movie Vámonos con Pancho Villa, directed by Fernando de Fuentes in 1936, in which some of the most representative exponents of Mexican culture of the momento gathered, in the work of the script, music or filmmaking. This film was conceived as a project subsidized by the state to promote the values in which they had founded both the Mexican Revolution as the legitimacy of the government in power, but careful reflection on the novel that gave birth to film production, as on the tape itself, its script or its original soundtrack as well as the personal trajectory and achievements of the artists involved in the project, show us tensions and contradictions which call into question the solvency of the revolutionary ideological official discourse.
\end{abstract}

Palabras clave: nacionalismo; revolución; cine; música; novela.

Keywords: Nationalism; Revolution; Cinema; Music; Novel. 


\section{Introducción}

Después de los años violentos de la Revolución Mexicana (1910 - 1920), comienza un proceso de reconstrucción nacional que acabaría por dar forma al México moderno. Si bien al principio la política cultural oficial estimuló un verdadero renacimiento artístico, abigarrado y plural, el panorama se estrecharía progresivamente en favor de una serie de hitos culturales, nacionalistas y excluyentes, patrocinados directamente por el gobierno: modelos programáticos para que las distintas manifestaciones artísticas dispusieran de su versión del dogma revolucionario en su labor de fijación y difusión simbólica del nacionalismo: la Novela de la Revolución, de corte realista, como modelo narrativo de la heroica hazaña revolucionaria; el muralismo pictórico, como desvelamiento en imágenes del ser mexicano, rural y mestizo; la música nacionalista, como descubrimiento del folklor y celebración de la comunidad; y el cine nacional, popularizador de los estereotipos del mexicano ejemplar, ya fuera heroico y revolucionario, moderno y urbano o rural y mestizo. Teniendo en cuenta estas coordenadas, la película Vámonos con Pancho Villa, dirigida por Fernando de Fuentes en 1936, representa un ejemplo paradigmático, no sólo de los logros de este programa, sino igualmente de sus contradicciones. En ella convergieron uno de los textos mayores de la Novela de la Revolución, la obra del mismo nombre de Rafael Muñoz, que sin embargo ofrece una visión desmitificadora del conflicto y de su famoso líder popular; la música de Silvestre Revueltas, principal exponente de la escuela nacionalista, pero a la vez el más universal y atípico de sus representantes; y, paradójicamente, la participación en la elaboración del guión del poeta Xavier Villaurrutia, miembro de los Contemporáneos, grupo conocido y, en su época, vituperado por representar precisamente la opción elitista, extranjerizante y universalista de la producción literaria mexicana posrevolucionaria.

\section{Novela de la Revolución}

Teniendo como precedente las disputas de la década anterior entre narrativa y poesía, entre la opción por la literatura épica, cívica, y la opción por una 
literatura 'menor' encarnada en López Velarde, la verdadera canonización de la expresión Novela de la Revolución tiene su origen en una polémica periodística desarrollada en varios diarios de la capital entre fines de 1924 y la primera mitad de 1925 sobre el carácter de la literatura nacional. Como toda polémica literaria de envergadura, el fenómeno propiciador en sí sólo es la punta del iceberg de una confrontación más profunda de tipo político o ideológico. En este caso el debate implicaba una pregunta sobre el presente y el futuro del proyecto revolucionario, es decir, sobre el alcance y definición de lo revolucionario, sobre "cuáles son sus obras y quiénes sus abanderados" (Díaz, 2003, p. 28). En un ambiente sociopolítico convulso se hace comprensible que una polémica literaria encerrara una cuestión más candente sobre el ser nacional. Teniendo como referente inmediato la repercusión nacional e internacional y la percolación social que había tenido el movimiento muralista desde comienzo de los años veinte, como orientación del arte hacia las masas, se sentía la necesidad de definir esa función social e instructiva del artista igualmente en el campo de las letras. Aparte del peso que todavía ejercían algunos de los antiguos ateneístas, y entre ellos González Martínez -si bien muchos de ellos se encontraban fuera de México-, este terreno de las letras, especialmente en lo referido a las jóvenes generaciones, aparecía hasta el momento ocupado por las rupturistas experiencias de la vanguardia estridentista o por la propuesta cultista y extranjerizante de los Contemporáneos, y, específicamente en el género narrativo, por la novela realista y costumbrista de tema colonial e indigenista. Era hora, pues, desde la perspectiva del gobierno, de promover la "producción de una literatura que sirviera a sus fines propagandísticos, tal y como los murales se prestaban a la retórica oficial” (Bruce-Novoa, 1991, p. 37).

La polémica giró en torno a los conceptos de virilidad y afeminamiento, cada uno de ellos pretendidamente asociado a una forma de entender el ejercicio de escritor y su relación con los problemas apremiantes de la sociedad. La dureza de los términos que se emplearon por parte del bando comprometido con la realidad nacional atacaba la orientación sexual de algunos de los miembros del grupo que después se conocería como Contemporáneos, a los que se les acusaba de escapismo y excentricidad intelectualista y de indiferencia ante los acuciantes problemas de la nación. Frente a las preocupaciones en exceso estilísticas y 
elitistas de este grupo, que ya gozaba de cierto poder y reputación en los medios públicos, los polemistas que se consideraban viriles reclamaban la necesidad de una literatura de la Revolución, una literatura comprometida con el pueblo, con la representación del ser nacional y con los valores del discurso revolucionario. Los experimentos modernistas, la curiosidad por las novedades literarias extranjeras o la introspección intelectual eran vistos como síntomas del afeminamiento y degradación de la literatura que se hacía en esos momentos y se lanzaba al aire la duda de si existía una obra literaria verdaderamente representante del movimiento revolucionario. Fue en el seno de este debate donde el término "Novela de la Revolución" comenzó a utilizarse para discutir si estaba ya escrita la obra que mereciese ese calificativo y cuáles debían ser las cualidades de la que lo mereciera, pues se daba por sentado que "un movimiento histórico trascendente debe tener sus grandes escritores, cuya función consistiría en redactar la crónica literaria de los sucesos" (Olea, 2012, p. 492). Una novela escrita en 1915 y que había pasado desapercibida, Los de abajo, de Mariano Azuela, se convirtió en el foco de discusión que canalizó muchas de las posturas de la polémica. La importancia de la polémica para la invención y difusión de la categoría de "Novela de la Revolución" es pues fundamental, hasta tal punto que Aguilar Mora asevera con contundencia que "la polémica de 1925 en torno a Los de abajo determinó el establecimiento de un género nuevo en la literatura mexicana" (Aguilar, 1990, p. 53). A partir de aquí el público lector se interesó por la obra de Mariano Azuela, primero, y se fue conformando, después, un mercado literario que demandaba productos bajo esta etiqueta retórica y comercial, que "tanto los periódicos como las casas editoriales y los escritores no tardaron en aprovechar" (Bruce-Novoa, 1991, p. 36). Tal es así que, según dice Felipe Garrido, "después de 1928, hasta llegar a los años cuarenta, la Revolución se convirtió en el tema más tratado por los narradores" (Garrido, 1989, p. 842) y, según Jorge Aguilar Mora, "para mediados de la década de 1940 se habían publicado alrededor de doscientas novelas y otros tantos cuentos sobre la Revolución" (Aguilar, 2011, p. 10). ${ }^{1}$ La Novela de la Revolución se convirtió en uno más de los mitos revolucionarios (Garrido, 1989, p. 842), que

1. Tanto Magaña Esquivel como Adalbert Dessau, en sus respectivos estudios sobre la Novela de la Revolución localizan en 1927-1928 el comienzo del auge de este género, (Magaña, 1964, p 16), (Dessau, 1986, p. 109). 
como todo mito de largo recorrido que se precie, a pesar de los intentos por ser desmontado, sigue rigiendo como categoría historiográfica y crítica para la explicación y comprensión de un período de la literatura mexicana.

Un aspecto que interesa discutir aquí brevemente es la contradicción existente entre el talante crítico de algunas de las novelas de la Revolución más celebradas y su usufructo ideológico por parte del régimen nacionalista revolucionario. El gobierno de Plutarco Elías Calles (1924-1928) había tomado un rumbo de nacionalismo exacerbado que se oponía a la vocación ateneísta, clásica y universalista de la política cultural del secretario José Vasconcelos durante el mandato del anterior presidente Obregón, y que tenía en "el antihispanismo, el folklorismo indigenista, la literatura de compromiso y la novela de la Revolución" algunos de sus hitos de demarcación identitaria de la cultura nacional (García, 2000, p. 250). Un factor que dota de cierta coherencia al conjunto y que han puesto de manifiesto prácticamente todos los comentaristas es el carácter crítico sobre la Revolución de esta narrativa, la mirada escéptica y desencantada que muchos de sus autores arrojan sobre los hechos que narran, lo que, como decimos, genera un cierto desajuste ideológico entre la perspectiva de la ficción y el discurso oficial que presumiblemente la patrocinaba y alentaba. Ya desde su nacimiento, con Los de abajo, que fue acusada de nihilista por algunos de su detractores (Olea, 2012, p. 493), va a emerger este contrasentido en tanto marca de identidad del género ${ }^{2}$, que recorre y atraviesa buena parte de su novelística como muestra del inconformismo y la libertad creativa por parte de unos autores que, por haber presenciado y vivido el horror de la guerra, y por dar voz en sus relatos a los que combatieron en ella, difícilmente podían congraciarse con un mero recuento celebrativo y épico de las turbulentas luchas. "Sus autores, nos dice José Luis Martínez, no siempre se mostraron de acuerdo con el desarrollo de la Revolución misma o con sus consecuencias prácticas, y no es extraño encontrar en sus obras el desencanto, la requisitoria y, tácitamente, el desapego ideológico respecto de la Revolución" (Martínez, 1997, p. 114). Pese a este criticismo, era esta la literatura que se había

\footnotetext{
2. La ambigüedad del género vendrá marcada ya desde sus inicios con Los de abajo, Aguilar Mora nos dice al respecto de las primeras críticas sobre la obra de Azuela que "la coincidencia de los argumentos de sus apologistas con las críticas de sus detractores le dio desde el principio al género una validez muy ambigua" (Aguilar, 1990, p. 53).
} 
propuesto contar los acontecimientos recientes de la Revolución, y estaba evidentemente más a la mano para hacerla rendir un beneficio ideológico que las propuestas de vanguardia formalmente innovadores y minoritarias, de los estridentistas, o la novela lírica y urbana que por los años veinte estaban practicando lo Contemporáneos, precisamente como alternativa a la Novela de la Revolución. ${ }^{3}$ Huelga decir que estridentistas y contemporáneos no se formaban en un mismo 'bando' frente a la novela revolucionaria, de hecho las disputas entre ellos conforman otro capítulo apasionante de la literatura posrevolucionaria; los aúna, en el contexto que aquí nos interesa, la imposibilidad de usufructuar su narrativa, experimental, iconoclasta desde el punto de vista de los cánones narrativos convencionales, para los fines propagandísticos del gobierno revolucionario. Por decirlo de alguna manera, las instituciones culturales mexicanas que se dedicaron a la propaganda del régimen tuvieron que conformarse, en su búsqueda de un formato narrativo que hiciera las veces de vocero del discurso hegemónico, con un conjunto de textos cuyo aspecto crítico y pesimista respecto de la propia Revolución era "una de las características fundamentales de su manera de ser” (Aub, 1971, p. 4). Aquí radica una importante contradicción del nacionalismo revolucionario que ha intentado ser abordada desde diversos puntos de vista. Desde un principio se atacó la novela por ser un simple relato anecdótico de los combates, para consumo de la clase media acomodada, sin pretensión de profundizar en las causas sociales y económicas que habían provocado el levantamiento del pueblo y, por tanto, sin ofrecer una visión de la totalidad del fenómeno y su progresión; los autores, a decir de Paúl Arranz, solo "nos dan instantáneas de la Revolución, pero se escamotea por lo general el contexto social de la lucha de las facciones y el análisis de las causas que llevan a situaciones de hecho" (Paúl, 1999, p. 53), de ahí que merecieran el denuesto por parte de las facciones más radicales comprometidas con la causa marxista. Se podría, desde esta interpretación,

\footnotetext{
3 . Por supuesto la referencia fundamental parael estudio de la novela que practicaron los Contemporáneos en los años veinte es el libro de la profesora Rosa García Gutiérrez Contemporáneos: la otra novela de la Revolución Mexicana. La tesis central de libro es que los Contemporáneos entendieron su producción narrativa "no como un mero ejercicio literario, puro virtuosismo artístico impulsado por su condición de artistas, sino como un deber, una alternativa necesaria al estereotipado nacionalismo cultural que se institucionalizaba en México en los años veinte" (García, 1999, p. 13).
} 
pues, achacar falta de compromiso con la ideología revolucionaria 4 a unos escritores que no se identificaban con la clase de campesinos humildes que habitaba sus relatos, a la cual, protagonista de la lucha real y de la ficción, le estaba vedada por contra una verdadera participación política entre las clases dirigentes, el ser el auténtico agente del cambio. El pesimismo, la desilusión, el desencanto por el fracaso de los ideales rezuma en estos relatos, y el resultado final invariablemente es una resignada despolitización del pueblo, que queda alejado de la política, como antes, después del paso avasallador y destructivo de la Revolución. Como dice Bruce-Novoa

La Revolución sigue adelante, casi incontenible, mientras el protagonista de la anécdota final queda aparte, enajenado y marginalizado...la Revolución, como acción política, queda alejada del ciudadano marginado. El resultado es que la acción política... se reduce a lo que los porfiristas nos decían, tratando de ponernos de sobreaviso: es un tabú para el ciudadano moral y bien intencionado (Bruce-Novoa, 1991, p. 39).

Quizá sea mucho, desde luego, esperar un claro posicionamiento ideológico por parte de los autores de estas novelas, una elaboración casi de tipo generacional de un concepto amplio, complejo y profundo de la Revolución, sus causas y su devenir, algo así como en los cincuenta haría, desde la academia, el Grupo Hiperion con la filosofía de lo mexicano. De un fenómeno revolucionario heterogéneo que se caracterizó por la ausencia de un ideario rector, que conllevó profundas diferencias regionales de intensidad y desarrollo, que sólo a partir de mediados de los treinta empezó a aglutinar, entre disputas y debates, el discurso oficial hacia posiciones socialistas, difícilmente puede esperarse que, en su versión estética ficcionalizada, pudiera arrojar la coherencia propositiva del panfleto político. Estas lecturas sobre la posible posición de clase desde la que se escribe el relato enriquece sin duda la interpretación del fenómeno cultural, pero creemos que neutraliza ese aspecto de crítica cultural y de politicidad implícita en el mismo al convertir finalmente a estos textos en poco menos que en cómplices del estado centralista y autoritario que no quiso llevar a término

\footnotetext{
4. Una ideología que no nació con la revolución, sino que fue fabricada por los gobiernos prorrevolucionarios para legitimar su poder, una ideología que se debió "a los deseos de los gobiernos 'revolucionarios' de Obregón y de Calles; a los propósitos de instaurar un discurso oficial" (Aguilar, 1990, p. 53).
} 
las metas emancipadoras del movimiento revolucionario. El discurso de la Novela de la Revolución interfiere con el discurso triunfalista y autocomplaciente de la historia oficial, entorpece e incomoda a la pedagogía estatal ofreciendo una interpretación alternativa de los hechos y sus consecuencias, una crónica áspera y dura, alejada de sutilezas de lo políticamente correcto, de la lucha y el fracaso. En palabras de Carlos Fuentes sobre Los de abajo, "impidió que la historia revolucionaria, a pesar de sus enormes esfuerzos en ese sentido, se nos impusiera totalmente como celebración épica" (Fuentes, 1983, p. 10). Esta narrativa otorga la voz al pueblo como colectividad incómoda con el proyecto oficial, permite aflorar identidades opacadas por una revolución institucionalizada y abre fisuras en un discurso con aspiraciones hegemónicas que no puede llegar a totalizar el rango de todas las subjetividades sociales, ofrece, siguiendo con Jorge Aguilar Mora, "la posibilidad de manifestar su original manera de percibir la Historia, de reflexionar sobre los acontecimientos históricos, [...] (de) comprender la posición existencial de los participantes en los hechos" (Aguilar, 2011, p. 178). Esta contradicción ha servido para que la Novela de la Revolución haya arrojado un saldo multivalente y proficuo como documento histórico y como ficción, inaugurando una corriente de autocrítica nacional (Lorente-Murphy, 1989, p. 851 ) en la que abundaron las composiciones más complejas y elaboradas de la novelística posterior.

Rafael Muñoz es uno de los principales representantes de la narrativa de la Revolución, con dos novelas en su haber y varias colecciones de cuentos. iVámonos con Pancho Villa! fue su primera novela, publicada en 1931; la particular estructura de este texto es consecuencia de su germen editorial. El autor colaboraba en el diario de la capital El Universal Ilustrado publicando semanalmente un cuento en la edición dominical. Al suspenderse la colaboración se quedó con 80 cuartillas ya escritas y sin destino, por lo que decidió completarlas con otro tanto para formar la que sería su primera novela (Suárez \& Pulido, 1979, p. XXVII). La novela cuenta la vida de seis campesinos del Norte de México, apodados los Leones de San Pablo, que deciden unirse al ejército de Pancho Villa; la primera parte de la novela está estructurada en capítulos que se cierran con la muerte de uno de los revolucionarios, la acción es 
rápida y contundente, se narran lo hechos bélicos sin digresiones ni paliativos, la prosa es seca y precisa, los capítulos tienen la consistencia del relato independiente, pues corresponden a los cuentos que vieron la luz por separado, y terminan, como decimos, con la muerte de uno de los protagonistas en condiciones trágicas o incluso absurdas, pero que siempre demuestran la fidelidad a la causa revolucionaria, y más aún, a su líder Pancho Villa, y un desprecio digamos casi nihilista por la vida. Los hechos se ubican en el año de 1914, cuando Villa y su mítica División del Norte se encuentran en el apogeo de sus éxitos militares, y su figura es la del héroe popular aclamado por las masas. Villa no aparece de forma directa pero su presencia se cierne tácitamente sobre los hechos narrados y condiciona el comportamiento de los protagonistas, es el faro de carisma indiscutido que, más allá de ideologías o motivaciones personales, justifica y anima el movimiento de la tropa, el compañerismo a ultranza y la fidelidad de los personajes a una Revolución cuyas causas socioeconómicas y políticas profundas se les escapan o les resultan indiferentes. La segunda parte presupone una elipsis temporal que presenta a Tiburcio Maya, el único superviviente de los Leones, ya retirado del combate trabajando el campo con su esposa e hijos. En su recuerdo perviven mitificados los hechos de guerra y espera en el fondo algún día volverse a unir a su antiguo jefe. La oportunidad se presenta cuando aparece el propio Villa con su diezmada tropa y le exige que se una a ellos, Tiburcio duda y alude que no puede abandonar a familia, Villa responde con una de las acciones más brutales e incomprensibles que la ficción y la historia hayan podido achacarle: mata a sangre fría a la mujer e hija para librar a Tiburcio de sus obligaciones familiares. El último león acaba uniéndosele con su hijo, demostrando una fidelidad casi sobrehumana. Esta segunda parte desarrolla un ritmo más lento que permite describir a Pancho Villa en pleno declive. Ahora es considerado un bandido por el régimen constitucional, los pueblos han formado cuerpos de defensa para repeler sus asaltos, se nos muestra solitario y desconfiado de sus propios hombres, siempre a la espera de la traición por la espalda. Si en la primera parte la ideología revolucionaria era difusa, inconcreta, ahora, desnudada del oropel del éxito militar parece que la mera rebeldía, el hábito de la vida clandestina une a estos villistas, ya sin esperanzas de triunfo, abocados al bandidaje y a la huida 
permanente. La suya es una fascinación irracional por la vida errática y aventurera de una existencia despojada de todo valor, que sólo encuentra una última motivación en el sentido de pertenencia que otorga la bola revolucionaria, el grupo de forajidos, que conserva a pesar de todo una fidelidad brutal y exasperada a un líder en su ocaso, a una causa revolucionaria lejana e irreal, a un compañero de tropa desconfiado y receloso. La fidelidad al grupo se ha despojado de todo valor abstracto, moral, político, religioso, el grupo construye su propia ética para justificar una resistencia y una fe libres de todo fin superior: la rebeldía por la rebeldía, la libertad por la libertad, se justifican a sí mismas, la pertenencia al colectivo parece otorgar todavía una identidad y un lugar, a pesar de ser testigo de su propia disolución.5 Tiburcio acepta la cruel liberación que le facilita el asesinato de su familia, y más aún cuando muere su hijo, que le había acompañado con los villistas, en el famoso ataque a pueblo estadounidense de Columbus, donde el propio Tiburcio salva la vida del caudillo. Más adelante él mismo se encarga de cuidar de Villa, cuando malherido se esconde de la expedición norteamericana que está en su busca. Finalmente, cuando Tiburcio es apresado, se niega a delatar a su jefe renunciando a la recompensa que ofrecen por su cabeza y en última instancia renunciado a la vida. La novela de Rafael Muñoz ofrece una imagen brutal y salvaje de la guerra, que va acabando uno por uno con los Leones de San Pablo, en condiciones sórdidas y hasta ridículas, sin que normalmente ofrezca a cambio recompensa alguna de tipo idealista o social para el pueblo o para los revolucionarios. La consecuencias sociales redentoras de la guerra, si existen, quedan muy lejos de la inmediatez de la vida de los combatientes, la perspectiva de la narrativa, trasladada a estos, no puede alcanzar lecturas ideológicas o políticas del suceso, que es vivido en su sentido vital, más próximo y humano, crudo y casi animal, sin posibles interpretaciones totalizantes, como un torbellino que ha trastocado irreversiblemente sus vidas, y en el que se entremezclan sin posibilidad de clarificación una esperanza legítima pero imprecisa con la brutalidad y la sinrazón ${ }^{6}$. El autor no se compromete, narra con

\footnotetext{
5. Como dice Jorge Aguilar Mora, "la Bola les dio a estos rancheros -y a miles de combatientes revolucionarios- el regalo precioso de encontrar su sitio" (Aguilar, 2011, p. 126).

${ }^{6}$. De nuevo Aguilar Mora sintetiza los rasgos psicológicos y emotivos de los combatientes: "ese territorio descarnado de la vida inmediata, de la vida en sus pulsiones más desolladas, de la vida en sus momentos
} 
tono árido y desapasionado, lo heroico es rápidamente desbaratado por la inutilidad del sacrificio, el carisma del líder contrasta con una violencia irracional que carece de ideales purificadores, buscar una ideología redentora a los hechos narrados resulta casi grotesco, el tono pesimista y nihilista estorba continuamente una lectura épica política de los sucesos, y si la hay es una épica en sordina, la del individuo y el pueblo, que descubre el sentido más descarnado, más doloroso, pero también más humano de la lucha y la resistencia anónimas.

\section{Cine mexicano y Trilogía de la Revolución}

El apogeo de la cinematografía clásica mexicana suele ubicarse en la llamada Época de Oro del Cine Mexicano, que se desarrolla entre los años cuarenta y mediados de los cincuenta (Sánchez, 2002, p. 76). La gestación de esta etapa coincide con un período de estabilidad política bajo la presidencia de Lázaro Cárdenas (1934-1940), que a mediados de los treinta consiguió eliminar opositores políticos y desplegar una política corporativista de conciliación nacional bajo el paraguas de una política cultural que financió directa o indirectamente a las diversas ramas de la creación artística. Pero fue sobre todo la alianza con los EEUU durante la segunda guerra mundial y los menoscabos que esta produjo en las industrias cinematográficas competidoras los factores que explican su dominancia. Durante esta época la industria de cine puso en circulación todo un aparato simbólico que buscó la identificación de la ciudadanía con los tipos que las clases dominantes estipularon como paradigma de la mexicanidad. Como dice Silva Escobar, las prácticas cinematográficas desarrolladas durante este período contribuyeron "a la colonización de una imaginario social[...] en la medida en que un mundo social y culturalmente heterogéneo como el mexicano se nos presenta a través de un conjunto limitado de personajes y estilos de vida que se convierten en el epítome de lo mexicano" (Silva, 2011, pp. 11-12). La consolidación de este nacionalismo basado en estereotipos sociales fijos fue a la par con la creación de la industria

más desnudos, de la vida con valores que no son universales, ni abstractos, ni generales, sino valores inciertos, imprecisos, azarosos, vertiginosos, en constante transformación, que operan entre los seres humanos cuando nos dejamos ser lo que realmente somos" (Aguilar, 2001, pp. 138-139). 
cinematográfica, y a medida que se construía y reforzaba un imaginario social mexicanista y folklórico se instauraba una organización de la producción nacional que seguía el patrón del star system norteamericano y estilísticamente adaptaba a un ambiente típicamente mexicano el patrón de los melodramas del realismo sentimental hollywoodiense.

Los cineastas mexicanos de la época aurea aprendieron de Hollywood la tipificación de los géneros, el lenguaje cinematográfico, el estilo narrativo y la construcción de personajes estereotipados, produciendo un tipo muy popular de melodrama campesino que tenía todos los ingredientes necesarios para el éxito en taquilla y para la promoción de una mitología de estrellas que convocara la admiración del público. Esta cinematografía constituyó un espacio discursivo en el cual una serie de discursos, prácticas y saberes perfectamente estandarizados y articulados constituyó un lenguaje con alto grado de unidad y coherencia, fácilmente asequible para el público, con unos códigos visuales y narrativos inmediatamente traducibles a la sensibilidad común, y que participó convenientemente en la hegemonía política en tanto buscaba neutralizar cualquier posible disenso con los comportamientos e identidades sociales que emanaban del discurso oficial. El Estado fue perfectamente consciente de la eficacia del cine para influir en las masas y modelar subjetividades en su empresa de construir la identidad del México moderno, de ahí el apoyo estatal con que contó el cine durante los años treinta y cuarenta. La industria fílmica mexicana fue uno más de los pilares que el Estado promocionaba desde su política cultural para construir la legitimidad del gobierno y granjearse el favor del pueblo suministrando iconos identitarios de fácil asunción por la mayoría. El cine se convirtió en un medio de masas donde se aprendía a ser un buen mexicano y educaba "a sus frecuentadores en un «sentimiento nacionalista»" (Monsiváis, 1987, p. 12). Desde esta perspectiva el cine llegó a estar más controlado que la narrativa, dado su mayor alcance entre las masas y la vulnerabilidad de un público mayoritariamente poco educado (Guerrero, 2007, p. 25).

La Novela de la Revolución siempre alimentó una línea de disconformidad o cuanto menos desencanto que el cine perdió durante el apogeo de su época 
dorada. En este sentido la comedia ranchera fue la fórmula definitiva a la que se consagró la industria del cine y con la que alcanzó estos objetivos, podríamos decir, sociológicos. Allá en el rancho grande, de 1936, y paradójicamente dirigida por el mismo Fernando de Fuentes, fue la exitosa cinta que inauguró este género y dio con la "fórmula comercial capaz de convertir al cine mexicano en una verdadera industria" (García, 1998, p. 83), abriendo las puerteas del mercado internacional al cine mexicano. Este formato naturalizaba un ambiente idílico de índole rural, totalmente libre de contradicciones de clase, y en la que los tipos estaban perfectamente definidos en consonancia con su extracción social, que no se ponía en entredicho. La Revolución como tema ideológico o moral desaparece por completo y los dilemas personales eran acentuados al máximo borrando de la pantalla toda posibilidad de conflicto social o político. Se trataba de un cine de escapismo, donde brillaron las figuras de Emilio Fernández en la dirección, Gabriel Figueroa en la fotografía y Mauricio Magdaleno en el guión, y que dio fama internacional a la cinematografía mexicana, con repercusión en toda Latinoamérica y España.

Algunas cintas fundamentales de este subgénero fueron por ejemplo Maclovia (1948) y El rapto (1953), dirigidas por Emilio Fernández, o Los tres García (1946) y Dos tipos de cuidado (1952), de Ismael Rodríguez. En estas películas únicamente la trama amorosa perturbaba la paz ancestral del escenario, cuyas tensiones eran resueltas en un desenlace positivo que redundaba en la conciliación armónica de las clases y en la perpetuación del sistema de dominación. La heterogeneidad de subjetividades sociales, étnicas y de clase son reducidas a un mestizaje unificador representado por el charro y la china poblana, como caracteres centrales del argumento, en torno a los cuales se organiza un universo de identificación nacional que tiene entre sus hitos dadores de sentido a la tradición musical vernácula, el folklore campesino, los bailes y trajes típicos, las artesanías y la arquitectura rural, el costumbrismo romántico o el lenguaje coloquial (Vidal, 2011, p. 59). El resultado es un mensaje de nacionalismo profundamente conservador que neutraliza el discurso crítico, en el que la Revolución es un mero marco desustancializado que únicamente aporta pintoresquismo a la trama. La injusticia social y las diferencias de clase aparecen como relaciones fosilizadas que garantizan la 
legitimidad del discurso hegemónico, capturando la movilidad social en estos estereotipos implícitamente conformes con el régimen social posrevolucionario.

La Revolución fue pues un tema fundamental y casi fundacional para el cine mexicano, dado que este se desarrolla y prospera en México en los mismos años en que se desata el conflicto armado y se despliegan los gobiernos nacionalistas revolucionarios. De esta forma, la Revolución va a aportar una serie de eventos y personajes "que iban a tener interés para todo el mundo" (Standish, 2008, p. 519) y que van a ser retomados una y otra vez por las producciones cinematográficas, bien sea de forma problemática y crítica, o como mero telón de fondo para la reproducción de estereotipos melodramáticos. Según ha dicho Julia Tuñón, la evolución temprana del cine mexicano acusa un proceso inverso al de la historiografía de la Revolución, pues esta, partiendo de interpretaciones apegadas a los hechos y comprometidas con sus ideales, evoluciona hacia un tono más científico y objetivo para recalar posteriormente, en los sesenta y setenta, en una corriente revisionista y crítica que apunta a denunciar las continuidades con el régimen prerrevolucionario y arroja un tono escéptico sobre los logros sociales del conflicto (Tuñón, 1995, p. 135). El decurso en el cine es más bien de signo contrario. El cine de los años veinte y treinta, de hecho, cuenta con películas dotadas de lucidez y sentido crítico, con pretensiones artísticas y de corte anticonvencional, que ponen al descubierto las contradicciones del conflicto y arroja un balance amargo y desencantado, cuestionando la retórica épica oficialista; este cine, sin embargo no tuvo respuesta en taquilla y pronto se vio desplazado por el género populista que iba a descollar durante la Época de Oro del Cine Mexicano. Así, conforme la industria se va consolidando a mediados de los treinta, el discurso va evolucionando hacia el acriticismo, la neutralidad política y la celebración y propaganda de los tópicos nacionalistas suministrados por la política cultural del Estado.

En este primer cine inconformista, podemos identificar, de un lado, una veta de cine indigenista o nacionalista liberal con películas como Rebelión (1933), Janitzio (1934), Redes (1936), que asumían los postulados más progresistas de la revolución en clara avenencia con la deriva izquierdista y socializante que 
había tomado el gobierno en los últimos años del maximato7 y que se consolidará durante la presidencia de Lázaro Cárdenas. Estas cintas se mostraban inconformes con la situación de obreros y campesinos, desarrollando un cine comprometido a la vez que crítico con los logros sociales del gobierno, que pretende reflejar el espíritu de lucha y superación de las culturas populares recurriendo al lenguaje y simbología de Sergei Eisenstein, que había estado en México dejando una perdurable huella (Vidal, 2011, p. 51).

De otro lado existió un cine crítico revolucionario, cuyo tema y personajes centrales son la Revolución y los revolucionarios, tanto la élite militar y gobernante como los caudillos populares y los integrantes anónimos de la bola, y que estaría paradigmáticamente representado por la conocida como "Trilogía de la Revolución” de Fernando de Fuentes. En estas cintas, que han sido consideradas como cimas del cine clásico mexicano, el desarrollo y destino de los acontecimientos y personajes están irremediablemente asociados al contexto histórico revolucionario, hasta tal punto que podría decirse que el hilo conductor de la película es el despliegue irracional y sin sentido del devenir de la Revolución, al que se enfrenta la mirada desencantada de un realizador poco dispuesto a dotarla de sentido y justicia. Como dice Pablo Piedras, "la obra de Fuentes desafía la retórica de la reconciliación nacional y el consenso político propios del momento de su producción, y representa la Revolución como una lucha que carece de motivaciones ideológicas" (Piedras, 2012, p. 118). El criticismo de estas cintas no se volvería a dar en el cine nacional hasta el nuevo cine mexicano de los años sesenta y setenta. La primera de ellas, El prisionero trece (1933), se nos presenta con los tintes de una tragedia griega en un contexto de corruptelas de las que no escapan ni el mando militar ni la clase civil acomodada, los acontecimientos se precipitan en un ambiente de caos y desorden dictados por la irracionalidad de la guerra donde nadie parece estar a salvo de ser condenado o fusilado por motivos que nunca se explicitan, con algo de cierto fatalismo kafkiano. En la segunda película, El compadre Mendoza (1933), de Fuentes repite magistralmente el estilo fatalista abocado a un desenlace trágico. En este caso el personaje principal pone los intereses

\footnotetext{
7. Período de la política posrevolucionaria mexicana dominada por la figura del Jefe Máximo de la Revolución Plutarco Elías Calles.
} 
personales y la propia supervivencia por encima de cualquier ideal político, y lo mismo confraterniza con los representantes del Gobierno como con el ejército zapatista, llegando a la traición de la verdadera amistad como última barrera tras de la cual sucumbe en un nihilismo destructivo. La Revolución es otra vez, como dice Julia Tuñón, "una hecatombe que cierra las opciones humanas, como la amistad, que no responde a ninguna razón valedera” (Tuñón, 1995, p. 142).

La última producción de la trilogía es Vámonos con Pancho Villa, realizada en 1935, y exhibida en 1936, y constituye, según Ayala, "la mejor adaptación de una novela mexicana que haya realizado el cine nacional" (Ayala, 1968, p. 23). Se considera a esta cinta la primera superproducción mexicana y la que de alguna manera cierra la etapa artesanal del cine. Tuvo un coste exorbitante para la época de un millón de pesos, y fue la primera producción de los estudios de la Cinematografía Latino Americana S.A. (CLASA), que cayó en bancarrota tras el fracaso en taquilla de la cinta (Vidal, 2011, p. 53). ${ }^{8}$ Parece ser que la iniciativa surgió al calor de un conflicto del gobierno mexicano con los EEUU a propósito de la cinta estadounidense iViva Villa! (1934), firmada por Jack Conway como director oficialmente reconocido, si bien en ella trabajaron Howard Hawks y William Wellm, donde una vez más se ofrecía una imagen de la revolución y su líder simplista, denigratoria y racista, a la que México respondió financiando íntegramente la propuesta de de Fuentes y aportando material bélico y vestuario (Peredo, 2009, p. 124). La película comienza con un preámbulo escrito en el que se anuncia la violencia y el carácter "desconcertante" de Villa, lo que de alguna manera nos pone sobre aviso de la imagen poco complaciente que se va a ofrecer del personaje y de la Revolución.

\section{PREAMBULO}

ESTA PELICULA ES UN HOMENAJE
A LA LEALTAD Y EL VALOR QUE
FRANCISCO VILLA, EL DES-
CONCERTANTE REBELDE MEXI-
CANO. SUPO INFUNDIR EN LOS
GUERRILLEROS QUE LE SI
GUIERON.

8. La película podría enclavarse dentro del género que Rosenstone llama "romance histórico": "producciones de alto presupuesto en que el vestuario, las locaciones auténticas, y los actores famosos toman precedencia frente a los intentos de precisión histórica" (Rosenstone, 2005, p. 98). 
El desencanto presente en la novela de Rafael Muñoz se aviene perfectamente con la visión sombría que el propio de Fuentes ya habría ofrecido en sus dos cintas anteriores de la trilogía. La película se centra básicamente en la primera parte del libro, aquella que recoge episódicamente escenas militares que normalmente acaban con la muerte de uno de los Leones de san Pablo, el grupo de villistas que protagoniza la historia. ${ }^{9} \mathrm{El}$ guión fue adaptado por el poeta y crítico Xavier Villaurrutia y supervisado por el dramaturgo Celestino Gorostiza, ambos miembros de grupo de los Contemporáneos, que se caracterizó por su alejamiento de las doctrinas nacionalistas del arte revolucionario y mexicanista promovido por el Estado. ${ }^{10}$ La perspectiva sombría y escéptica del original es acentuada si cabe en el guión, especialmente en la escenas añadidas para salvar el carácter fragmentario del relato, dando continuidad narrativa al montaje. En estas escenas la cámara se acerca a la intimidad de los personajes, sesgo del todo ausente en la novela, filmando conversaciones entre los amigos en la que se pone en duda, cada vez con mayor escepticismo, el sentido de la Revolución.

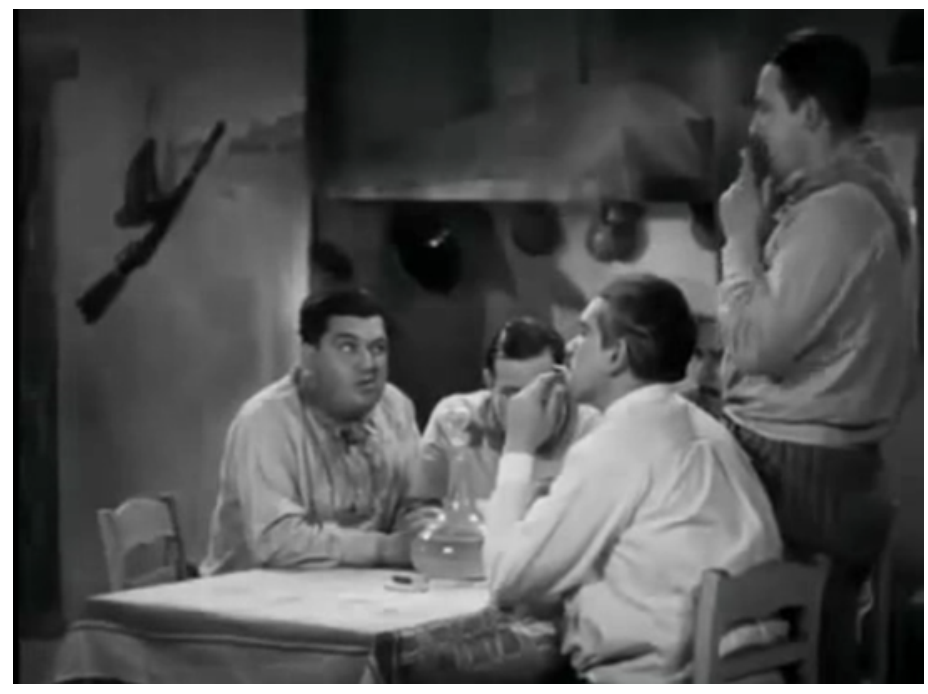

\footnotetext{
${ }^{9}$. Nos encontramos con un protagonista colectivo, no sólo los mismos integrantes de los Leones de San Pablo, sino, en definitiva, todo el ejército villista y, en general, la masa anónima que tomó partido en la Revolución y que están simbólicamente representados por este grupo de combatientes que protagoniza la novela y película. Dice Rosenstone al respecto que "el cine tiende a destacar a los individuos por sobre los movimientos o los procesos impersonales que a menudo son el tema de la historia escrita, pero no hay que olvidar que es posible realizar filmes que eviten la glorificación individual y donde el protagonista sea un grupo" (Rosenstone, 2005, p. 99).

${ }^{10}$. Para un comentario sobre la relación de Xavier Villaurrutia y los Contemporáneos con el cine ver los trabajos de Miguel Capistrán, Aurelio de los Reyes, Louis Panabiere y Gustavo García citados en la bibliografía.
} 
Desde el entusiasmo con que acogen la causa villista los Leones al principio, la película va alejando progresivamente a sus protagonistas de cualquier ideología o sentido de la justicia que la justifique, convirtiéndola en una lucha amoral cuyo único fin es dirimir la hombría y valor de los participantes. El sinsentido va en aumento, pues si las primeras muertes son en el campo de batalla, llegamos a una secuencia en la que uno de los Leones encuentra su final en una especie de juego de ruleta rusa entre borrachos en una cantina.

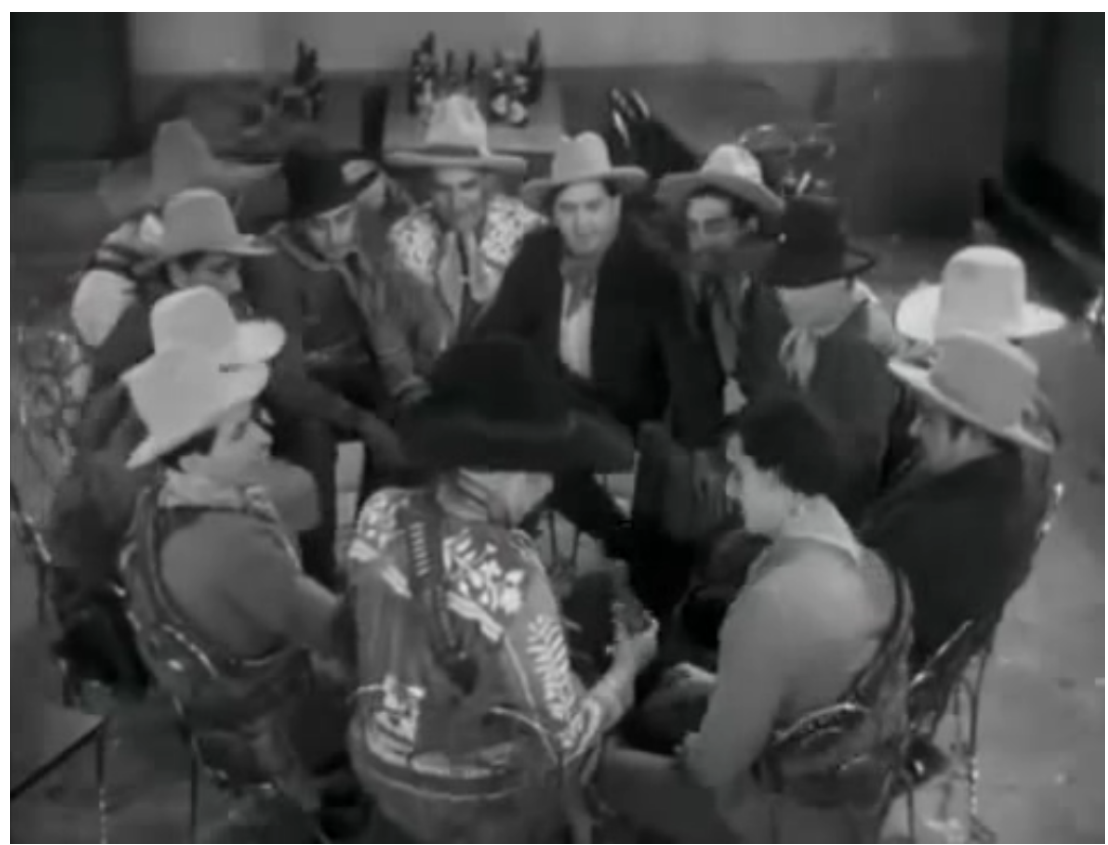

El punto culminante para el desengaño revolucionario llega con la escena final en la que Tiburcio Maya se ve obligado por órdenes de Villa a quemar a su último compañero enfermo de viruela para evitar el contagio al resto de la tropa. La crudeza despiadada conque los mandos tratan a un revolucionario que ha dado su vida por la Revolución acaba de minar el sostén moral de Tiburcio, que cuando comprueba el temor del propio Villa a contagiarse de la viruela se decide a desertar de la guerra. 


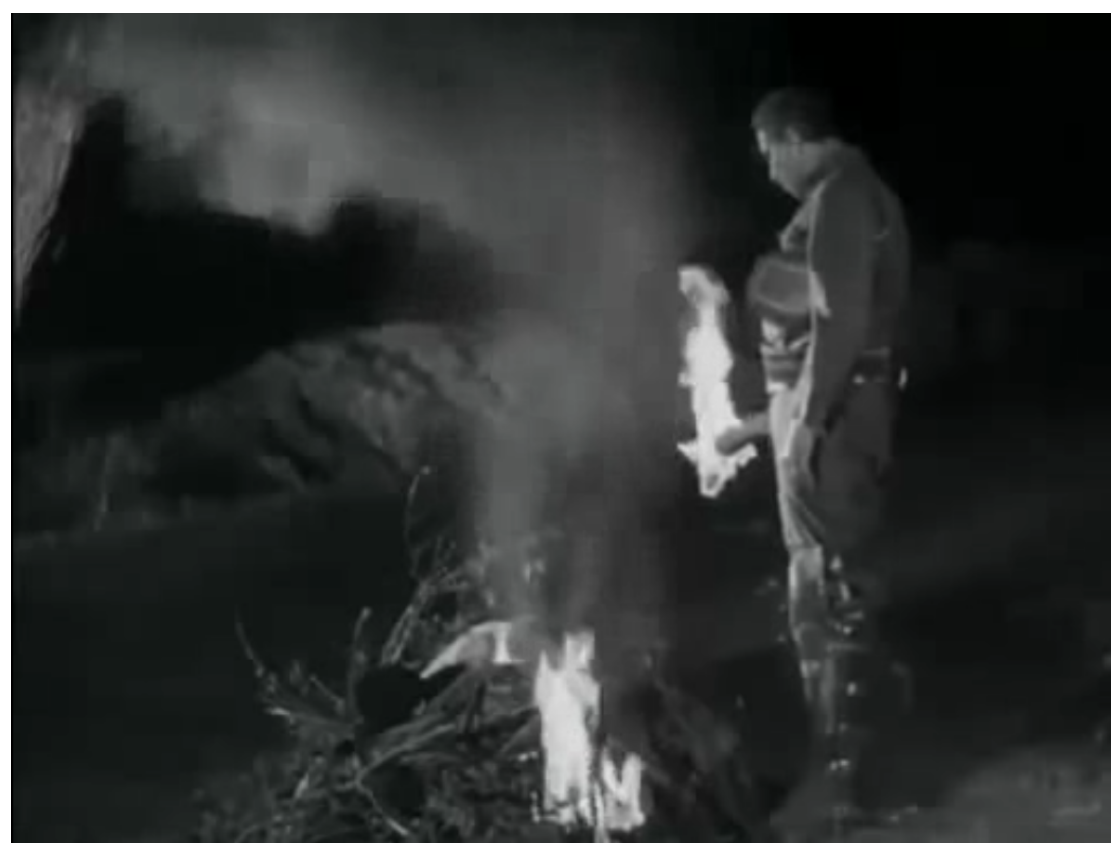

Si bien se trata de una gran producción con aliento épico en las escenas de batalla, la retórica celebrativa se ve continuamente desmontada, en un juego de contrapesos que funciona a lo largo de todo el metraje, por escenas cómicas que descargan el patetismo y por una música incisivamente burlona e irreverente, muy al estilo de Silvestre Revueltas, que trivializa el tinte dramático de los sucesos. ${ }^{11}$ La magnífica música original de Revueltas para esta película combina momentos brillantes y festivos y melodías jocosas con cortes abruptos de tono luctuoso, especialmente en las escenas bélicas lo lúdico parece darse la mano con lo trágico, arranques celebrativos de aire marcial o melodías de corridos y canciones populares se entretejen con pasajes descriptivos de corte vanguardista y experimental con gran riqueza tímbrica y complejas texturas sonoras. Los momentos trágicos, como las muertes de los revolucionarios, nunca son ilustrados con una pátina sonora romántica y melodramática, sino que la imagen está siempre punteada con toques de ironía que apuntalan perfectamente la ambigüedad tragicómica que atraviesa la película. El tono

\footnotetext{
${ }^{11}$ Revueltas es siempre un músico originalísimo e inadaptable a los cánones retóricos del nacionalismo, plasmando en su música su personal búsqueda sonora y elucubrando por senderos propios su personal versión de la música mexicana y del arte comprometido, más próximo seguramente de la experimentación europea de Debussy o Stravinski, que de los maestros románticos nacionales y del nacionalismo de escuela. Aunque adoptara en sus manifestaciones públicas la retórica de la ortodoxia socialista de un arte para el pueblo, no cabe duda de que jamás Revueltas se plegó en sus innovadoras creaciones musicales a la doctrina de arte de consigna y de panfleto, "comprometido y eficaz que propugnaba Chávez para consumo de las masas" (Moreno, 1994, p. 164) en los años treinta.
} 
general de la partitura no permite fáciles complacencias con el discurso nacionalista, y hasta podría interpretarse como una sátira de lo que sería la banda sonora de la Revolución, muy de acuerdo con la intención desmitificadora de la novela y el guión. La película incluía un final alternativo que parece haber sido censurado por el propio presidente Cárdenas y en el que se recogía con toda crudeza la brutalidad de la escena en la que el propio Villa acababa con la vida de la esposa e hija de Tiburcio, para liberar a este de obstáculos en su reincorporación a las tropas revolucionarias.

\section{Conclusión}

Una cinta absolutamente emblemática del nacionalismo revolucionario promovido y promocionado por el gobierno mexicano posrevolucionario y, sin duda, una de las cimas de la época de oro del cine de este país contiene, tanto en su proceso de producción como en su resultado final, las suficientes complejidades y tensiones internas como para poder ser leída a contracorriente de su supuesta ideología revolucionaria. Esta relectura permite arrojar una nueva luz sobre la película que ilumina de forma ejemplar la propia dificultad que los discursos oficiales institucionalizados encontraron a la hora de instrumentalizar los productos artísticos y culturales como aparatos ideológicos del estado para homogeneizar una cultura nacional y nacionalista compacta y sin fisuras. Hemos podido ver cómo el género o subgénero de la Novela de la Revolución fue recogido y aprovechado inmediatamente después de su nacimiento en los años veinte por el discurso oficial como el relato de la verdadera hazaña popular de la revolución triunfante. No obstante, esta novelística nos muestra un mundo, que cabalga entre la cruda crónica de guerra y la ficción realista, que muy poco tiene que ver con la apología simple y llana de unos heroicos hechos de guerra o con un posible fácil acomodamiento dogmático de sus autores con la ideología revolucionaria que el gobierno estaba construyendo para el adoctrinamiento de las masas. Algunas de las mejores y más leídas novelas de la Revolución y, sin duda, Vámonos con Pancho Villa, de Rafael F. Muñoz, es un ejemplo descollante entre ellas, exponen una visión crítica y desencantada de los acontecimientos revolucionarios, en los que se 
destacan más la heroicidad anónima del pueblo que la épica de un destino nacional, más la irracionalidad y el cruento patetismo que todo hecho bélico comporta que algún improbable idealismo redentor, más las historias personales truncas, devastadas o enaltecidas por el torbellino de la guerra que la historia totalizante de una patria que las envuelva y justifique. Partiendo de este material literario complejo y preñado de potenciales contradicciones, una adaptación cinematográfica llamada a perdurar en el tiempo por encima y más allá de gobiernos propicios, no podía permitirse llevar a la pantalla un versión deslavada, apologética y roma, sino que es precisamente su riqueza como punto de encuentro y diálogo de diferentes discursos ideológicos y estéticos lo que la hace especialmente interesante para nosotros. Como adaptación cinematográfica la cinta encuentra sus recursos narrativos e ideológicos más interesantes precisamente en aquellos episodios que más lejos están de las escenas espectaculares que le han dado la fama merecida de primer gran superproducción del cine mexicano. Como se dijo arriba, el guión se encargó al poeta y ensayista Xavier Villaurrutia, y su revisión al dramaturgo Celestino Gorostiza, ambos vinculados al grupo de los Contemporáneos, grupo estética e ideológicamente antagónico a todo discurso y estética nacionalistas y revolucionarios, de ahí que las escenas añadidas por los guionistas remarquen con conversaciones entre los protagonistas las dudas sobre su incorporación a la División del Norte y el sentido y fin de la propia Revolución. En cuanto a la música, ya se ha dicho que el compositor Silvestre Revueltas, que sin duda figura entre los máximos exponentes del nacionalismo musical mexicano, es a la vez un músico de un individualismo irreductible a ningún dogma de escuela, poseedor de un instinto peculiar para captar el espíritu de la música popular y transformarlo, sin reproducciones literales, bajo la técnica y los hallazgos de las vanguardias musicales, en un estilo muy personal y a veces complejo. Personalidad y estilo que le valieron en más de una ocasión desencuentros con Carlos Chávez, el músico y hombre de estado creador y divulgador entre las masas del mexicanismo musical oficialista. Revueltas diseña para la película de De Fuentes una partitura cargada de la ironía y el humor tan propios de su manera, desarticulando, como ya se ha sugerido, con complejas sonoridades 
modernistas entreveradas de sones y melodías de inspiración popular, cualquier posibilidad de retoricar una epopeya musical de regusto romántico.

En definitiva, Rafael Muñoz, Fernando de Fuentes, Xavier Villaurrutia, Celestino Gorostiza y Silvestre Revueltas, todos comprometidos, explícita o implícitamente, en algún momento de sus trayectorias artísticas, con proyectos de alguna manera alternativos al discurso oficial del gobierno revolucionario del México de los años 30, convergieron en la cinta Vámonos con Pancho Villa, dando lugar a un producto que es ejemplo paradigmático de cómo la libertad artística desborda y deconstruye los discursos ideológicos dogmáticos y monolíticos.

\section{Referencias bibliográficas}

Aguilar Mora, J. (1990). Una muerte sencilla, justa, eterna. Cultura y guerra durante la Revolución Mexicana. México D.F.: Era.

Aguilar Mora, J. (2011). El silencio de la Revolución y otros ensayos. México D.F.: Era.

Aub, M. (1971). De algunos aspectos de la novela de la Revolución mexicana. Diálogos: Artes, Letras, Ciencias humanas, 7 (1), 4-11.

Ayala Blanco, J. (1968). La aventura del cine mexicano. México D. F.: Era.

Bruce-Novoa, J. (1991). La novela de la Revolución Mexicana: la topología del final. Hispania, 74 (1), 36-44.

Capistrán, M. (1994). Los Contemporáneos por sí mismos. México D.F.: CONACULTA.

Castro Leal, A. (1988). La Novela de la Revolución Mexicana. México D.F.: SEP/Aguilar.

Dessau, A. (1986). La Novela de la Revolución mexicana. México D.F.: Fondo de Cultura Económica.

Díaz Arciniega, V. (2010). Querella por la cultura "revolucionaria" (1925). México D.F.: Fondo de Cultura Económica.

Fuentes, C. (1983). La Illíada descalza. Vuelta, 80, 5-10.

Fuentes, F. de (1936). Vámonos con Pancho Villa. México: Clasa.

García, G. (1994). Que los que se aman sufran de modo tan poco jurídico: los Contemporáneos y el cine. En R. Olea Franco y A. Stanton (Eds.), Los Contemporáneos en el laberinto de la crítica (pp. 173-179). México D.F.: El Colegio de México.

García Gutiérrez, R. (1999). Contemporáneos: la otra novela de la Revolución Mexicana. Huelva: Universidad de Huelva. 
García Gutiérrez, R. (2000): “Archipiélago de Soledades” y otros tópicos sobre los Contemporáneos: lo mexicano según Cuesta. En Carmen Alemany Bay, Remedios Mataix, José Carlos Rovira y Pedro Mendiola Oñante (Eds.), La isla posible. Actas del III Congreso de la Asociación Española de Estudios Literarios Hispanoamericanos (pp. 248-258). Alicante: Universidad de Alicante.

García Riera, E. (1998). Breve historia del cine mexicano. México D.F.: Mapa.

Garrido, F. (1989). ¿Revolución en las letras?. Revista Iberoamericana, 148149, pp. 841-845.

Guerrero, M. C. (2007). El discurso en la novela y el cine de la Revolución mexicana. Revistas de Humanidades: Tecnológico de Monterrey, 23, pp. 13-39.

Lorente-Murphy, S. (1989). La Revolución Mexicana en la novela. Revista Iberoamericana, 148-149, pp. 847-857.

Magaña Esquivel, A. (1964). La Novela de la Revolución, tomo 1. México D. F.: Instituto Nacional de Estudios Históricos de la Revolución Mexicana.

Martínez, J. L. (1997). Problemas literarios. México D.F.: CONACULTA.

Monsiváis, C. (1987) El difícil matrimonio entre Cultura y Medios Masivos. Chasqui, 22, pp. 6-16.

Moreno Rivas, Y. (1989). Rostros del Nacionalismo en la Música Mexicana. México D. F.: Fondo de Cultura Económica.

Muñoz, R. F. (1979). iVámonos con Pancho Villa!. Se llevaron el cañón para Bachimba. ¿Historia, novela? (relato de la expedición punitiva). México D. F.: Promexa.

Muñoz, R. F. (2008). Vámonos con Pancho Villa. México D.F.: Era.

Olea Franco, R. (2012). La novela de la Revolución Mexicana: una propuesta de relectura. Nueva revista de filología hispánica, 60 (2) pp. 479-514.

Panabière, L. (1994). Contemporáneos y “L'Esprit Nouveau”: el cine. En R. Olea Franco y A. Stanton (Eds.), Los Contemporáneos en el laberinto de la crítica (pp. 181-186). México D.F.: El Colegio de México.

Paúl Arranz, M. M. (1999). La novela de la Revolución Mexicana y la revolución en la novela. Revista Iberoamericana, 65 (186), pp. 49-57.

Peredo Castro, F. M. (2009): La diplomacia del celuloide entre México y Estados Unidos: medios masivos, paranoias y la construcción de imágenes nacionales (1986-1946). Revista Mexicana de Política Exterior, 85, pp. 93-135.

Piedras, P. (2012). Las narrativas sobre la Revolución en el cine de Fernando de Fuentes y Emilio Fernández. En Representación y revolución en el cine latinoamericano del período clásico-industrial: Argentina, Brasil, México. Recuperado de http://www.fundacioncarolina.es/wpcontent/uploads/2014/o8/AI73.pdf [22/11/2015]. 
Reyes, A. (1994). Aproximación de los Contemporáneos al cine. En R. Olea Franco y A. Stanton (Eds.), Los Contemporáneos en el laberinto de la crítica (pp. 149-171). México D.F.: El Colegio de México.

Reyes, A. (1983). Los Contemporáneos y el cine. Anales del instituto de Investigaciones Estéticas, 13 (52), pp. 167-186.

Rosenstone, R. A. (2005). La historia en imágenes/la historia en palabras: reflexiones sobre la posibilidad real de llevar la historia a la pantalla. Istor, 5 (20), pp. 91-108.

Sánchez, F. (2002). Luz en la oscuridad. Crónica del cine mexicano (19862002). México D.F.: Casa Juan Pablos/Cineteca Nacional.

Silva Escobar, J. P. (2011). La Época de Oro del cine mexicano: la colonización de un imaginario social. Culturales, 8 (13), pp. 7-30.

Standish, P. (2008): Desarrollo del cine mexicano. En Acortando distancias: la diseminación del español en el mundo. XLIII Congreso de la AEPE (pp. 519-528). Madrid: AEPE.

Suárez Argüello R. y Pulido, M. A. Prólogo. En iVámonos con Pancho Villa!. Se llevaron el cañón para Bachimba. ¿Historia, novela? (relato de la expedición punitiva) (pp. IX-XXIX). México D. F.: Promexa.

Tuñón, J. (1995). La Revolución Mexicana en celuloide: la trilogía de Fernando de Fuentes como otra construcción de la historia. Anuario Colombiano de Historia Social y de la Cultura, 22, pp. 134-144.

Vidal Bonifaz, M. R. (2011). Racionalidad burocrática y dominación carismática: el cine mexicano como estrategia del Estado Nacional en México. Revista del Centro de Investigación de la Universidad La Salle, 9,(35) pp. 45-65.

Cómo citar: Fernández Mora, V. J. (2017). El nacionalismo cultural mexicano y sus contradicciones en la película Vámonos con Pancho Villa. Fotocinema. Revista científica de cine y fotografía, $\mathrm{n}^{\mathrm{o}}$ 14, pp. 19-42. Disponible: http://www.revistafotocinema.com/ 
